University of Nebraska - Lincoln

DigitalCommons@University of Nebraska - Lincoln

Sociology Department, Faculty Publications

Sociology, Department of

8-2007

Poverty Duration, Maternal Psychological Resources, and Adolescent Socioemotional Outcomes

Bridget J. Goosby

University of Nebraska-Lincoln, bgoosby2@unl.edu

Follow this and additional works at: https://digitalcommons.unl.edu/sociologyfacpub

Part of the Sociology Commons

Goosby, Bridget J., "Poverty Duration, Maternal Psychological Resources, and Adolescent Socioemotional Outcomes" (2007). Sociology Department, Faculty Publications. 168.

https://digitalcommons.unl.edu/sociologyfacpub/168

This Article is brought to you for free and open access by the Sociology, Department of at DigitalCommons@University of Nebraska - Lincoln. It has been accepted for inclusion in Sociology Department, Faculty Publications by an authorized administrator of DigitalCommons@University of Nebraska - Lincoln. 


\title{
Poverty Duration, Maternal Psychological Resources, and Adolescent Socioemotional Outcomes
}

\author{
Bridget J. Goosby \\ Program for Research on Black Americans, Institute for Social Research, \\ University of Michigan-Ann Arbor
}

\begin{abstract}
This study seeks to assess the impact of maternal psychological well-being on the depression and anxiety levels and social withdrawal in a sample of young African American and Caucasian adolescents between the ages of 10 and $14(N=854)$ using data from the National Longitudinal Survey of Youth 1979 child sample. Analyses using structural equation modeling found (a) that the duration of time mothers spend in poverty strongly predicts maternal mastery and depressive symptoms and (b) that the effects of poverty duration on adolescent outcomes are mediated primarily by maternal depression and sense of mastery even after controlling for parenting behavior and other familial background characteristics.
\end{abstract}

Keywords: mental health, poverty, adolescent, race, depression

$\mathrm{T}$ he number of households with children living in poverty declined steadily throughout the 1990s and began climbing again in 2000 (U.S. Bureau of the Census, 2006). Although poverty rates remain lower than they were throughout most of the 1990s, increasing numbers of families are living in poverty, and in 2005, there were approximately $14.5 \%$ of children under the age of 18 that lived in poverty among all family types, whereas $36.2 \%$ in single-parent families resided in poverty (U.S. Bureau of the Census, 2006). Evidence suggests that although increases in ma-

I would like to express my gratitude to Jacob E. Cheadle, Olatokunbo Fashola, Cleopatra H. Caldwell, and George Farkas for their helpful comments on various stages of this article. I would also like to thank the anonymous reviewers for Journal of Family Issues for their helpful comments. This article was developed as part of my doctoral dissertation, which was supported by a fellowship from the American Sociological Association and the National Institute of Mental Health. 
ternal employment during the 1990s contributed to the decline in poverty, racial disparities in the number of families with children in poverty remain unmitigated (Moffitt, 2002). Although some of the more striking shifts in poverty rates occurred for African American children, much of the change was likely the result of movement out of the most severely poor category into nearly poor status. Qualitatively, these shifts probably do not indicate a significant change or decline in ecological or contextual challenges for low-income youth (Lichter, Qian, \& Crowley, in press). Of the challenges associated with poverty status, family processes play a key role in influencing adolescent well-being, specifically through parents' psychological resources (McLoyd, 1990, 1998).

Previous research exploring the direct impact of poverty on adolescent outcomes indicates that adolescents who experience poverty are more likely to engage in drug and alcohol use at earlier ages, initiate sexual activity earlier, have increased mental health problems, and have lower levels of academic achievement (Brooks-Gunn \& Furstenberg, 1989; Duncan \& Brooks-Gunn, 1997; Duncan, Brooks-Gunn, \& Klebanov, 1994; Haveman \& Wolfe, 1994). Although adolescents spend most of their time in the company of their peers, families continue to play an important role in their lives. Critical familial factors that influence the lives of adolescents include maternal psychological well-being and parenting behavior, both of which can be affected by economic hardship and in turn may lead to deleterious consequences on adolescent well-being (Conger, Ge, Elder, Lorenz, \& Simons, 1994; McLoyd, 1990). Specifically, McLoyd (1990) argues that a major mediator between economic hardship and parenting behavior is parental psychological distress stemming from negative, chronic undesirable events and/or the absence of or disruption to marital bonds. Poverty diminishes the ability of parents to provide supportive, consistent behavior and involved parenting and may render parents more vulnerable to debilitating effects of these stressful life events.

Women in poverty experience more psychological distress because of the experience of chronic burdens resulting from financial stress, being the sole childrearing adult in a household, poor health, increased sense of powerlessness, and more depressive symptoms (Ensminger, 1995; Gutman, McLoyd, \& Tokoyawa, 2005; Lempers \& Clark-Lempers, 1990; Mirowsky \& Ross, 1989). By exploring the mediating influence of maternal psychological well-being on the relationship between poverty duration and adolescent socioemotional outcomes, this study seeks to further elaborate the relationship between the family and adolescent experiences using a sample of mothers and their adolescent children from the National Longitudinal Survey of Youth 1979 cohort (NLSY79). The article is organized around the following questions: (a) How does the duration of 
time spent in poverty directly influence early adolescent socioemotional outcomes? (b1) To what extent do maternal psychological resources directly affect adolescent socioemotional outcomes, and (b2) do these psychological resources serve as mediators in the relationship between economic hardship and adolescent outcomes net of parenting behaviors? Finally, (c) to what degree does poverty actually predict a mother's own depressive symptoms and sense of mastery?

\section{Poverty Experiences, Adolescent Well-Being, and Maternal Psychological Resources}

Experiencing persistent poverty over the life course can have adverse effects at all developmental stages and has been consistently linked to both child socioemotional well-being and parent well-being (Duncan et al., 1994; Korenman, Miller, \& Sjaastad, 1995; McLeod \& Shanahan, 1993; McLoyd, 1998). Children who are in families experiencing persistent economic hardship also have greater difficulties with peer relationships, more conduct problems at school, and lower self-esteem than children who experienced poverty intermittently (Bolger, Patterson, Thompson, \& Kupersmidt, 1995). Persistently poor adolescents also report higher levels of loneliness and depression (Lempers, Clark-Lempers, \& Simons, 1989). The risk of these events increase as the duration of time spent in poverty increases. Families living in poverty persistently represent the most disadvantaged strata and live in more harsh conditions, many lacking social support; living in unsafe, overcrowded environments; and lacking stable, consistent employment, which increase stress in the household (McLoyd, 1998). Stress in the family caused by economic strain manifests into depression, anxiety, feeling a lack of control in parents, and is linked to externalized behaviors in boys and internalized behaviors in girls in adolescence (Elder, 1999; McLoyd, 1990).

The coexistence of family risk factors such as parents' employment and educational status, family size, maternal mental health, unsafe living environment, and parenting behaviors contribute to the increased risk of negative outcomes for adolescents from low-income households (Gutman et al., 2005; Stiffman, Hadley-Ives, Elze, Johnson, \& Dore, 1999). The presence of maternal mental illness, large family size, or severe family discord can also dramatically increase the risk of poor outcomes for adolescents and their parents (Kim et al., 2003). Maternal mental health is an important factor in explaining the outcomes of poor youths. There is a notable relationship between socioeconomic status and psychological distress and mental disorders where the increase in socioeconomic disadvantage is associated with a higher risk of psychological distress 
and disorders (Miech, Avshalom, Moffitt, Wright, \& Silva, 1999). Persons continuously living in poverty are exposed to frustration-producing experiences (Liem \& Liem, 1978) and deal with an unremitting succession of negative life events. These events, including eviction and physical and mental illness, may exist in the broader context of chronically stressful life conditions that families face constantly, such as inadequate housing and unsafe neighborhoods (McLoyd, 1990).

Experiencing stressful life events and/or chronic strains can lead to adverse effects on self-concept, including mastery (Pearlin, 1999), which is defined as the extent to which the individual regards his or her life chances as being under their own control in contrast to being fatalistically ruled (Pearlin \& Schooler, 1978). When mastery is diminished, individuals are left especially vulnerable to symptoms of stress, including depression. Lower socioeconomic status is a factor that is negatively related to feelings of mastery or control over one's self and one's environment through its relationship with educational attainment, job status, and family income (Mirowsky \& Ross, 1989; Wheaton, 1999). These feelings of distress, depression, and anxiety tend to be elevated among people who feel that they have little influence over the events that occur in their lives (Ross \& Sastry, 1999). The relationship between persistent poverty, declines in mastery, and increases in depressive symptoms have implications over the life course, with the harmful influence of economic disadvantage playing out over various developmental stages (Podruvska, Schieman, Pearlin, \& Nguyen, 2005).

Mothers experiencing stressful life events such as economic hardship are more likely to have higher levels of depression and anxiety and lower levels of mastery. These psychological resources may manifest themselves in parenting behaviors, thus influencing their children's well-being (McLoyd, 1990). In addition, mental health disorders dramatically decrease the likelihood poor mothers obtain and consequently sustain employment (Jayakody \& Stauffer, 2000). The various stressors in the lives of low-income mothers such as inflexible work hours, pooling together adequate financial resources, difficulty with childcare arrangements associated with mental health problems, and for African American women the added stress of the perception of racial discrimination have been linked to declines in mental and physical health (McLoyd, Jayaratne, Ceballo, \& Borquez, 1994; Menaghan, Kowaleski-Jones, \& Mott, 1997; Williams, 1999). These symptoms, in turn, are related to involuntary and voluntary declines in supportive behavior on the part of mothers, including being less attentive to their children, alternating between disengagement and intrusiveness, showing lower emotional reciprocity, and having more negative affect toward their children (Luthar, 1999; McLoyd, 1990). 
Several studies testing the effects of persistent poverty on internalized and externalized outcomes have demonstrated a relationship. In these studies, the child outcomes were measured through late childhood and early adolescence from ages 10 to 14 with nationally representative samples and supported the argument that persistent poverty is mediated by maternal mastery, depressive symptoms, and self-esteem (McLeod \& Nonnemaker, 2000; McLeod \& Owens, 2004; McLeod \& Shanahan, 1993). Notably, these studies did not find differences in mediating relationship of parenting behavior and maternal mental health on poverty and child outcomes by race. However, they did find that persistent poverty had stronger effects on Caucasian adolescents' behavioral problems than on African American adolescents (McLeod \& Nonnemaker, 2000; McLeod \& Shanahan, 1993, 1996). Further research on family processes, specifically in low-income minority families, were examined by testing the pathways through which economic hardship effects child and adolescent outcomes through parent psychological distress, parenting behaviors, and child and adolescent outcomes (Gutman et al., 2005; Mistry, Vandewater, Huston, \& McLoyd, 2002). Although the authors demonstrated the strong contribution of parental mental health and parenting behaviors on low-income youth outcomes, they did not report the direct mediating relationship of maternal mental health on youth outcomes after taking parenting behavior into account. Although these studies have examined the mediating relationships of parenting behavior and parental psychological distress on adolescent well-being, more attention should be paid not only to how these mechanisms operate with chronic poverty but also to the relative magnitudes of maternal mental health and parenting behavior on adolescent outcomes.

\section{Contributions of the Present Study}

This study contributes to the prior research by addressing the extent to which maternal psychological resources (i.e., maternal depressive symptoms and mastery) mediate the relationship between poverty duration and adolescent socioemotional outcomes before and after taking parenting behavior into account and exploring which factors play the strongest roles in predicting maternal depression and mastery (see Figure 1). Using a national sample of African American and Caucasian adolescents and their mothers, the study focuses on economic hardship, which is operationalized as poverty duration in accord with previous research suggesting that the increasing duration of persistent poverty is harmful to those who experience it. Furthermore, mastery or sense of control and depressive symptoms among parents plays an important 


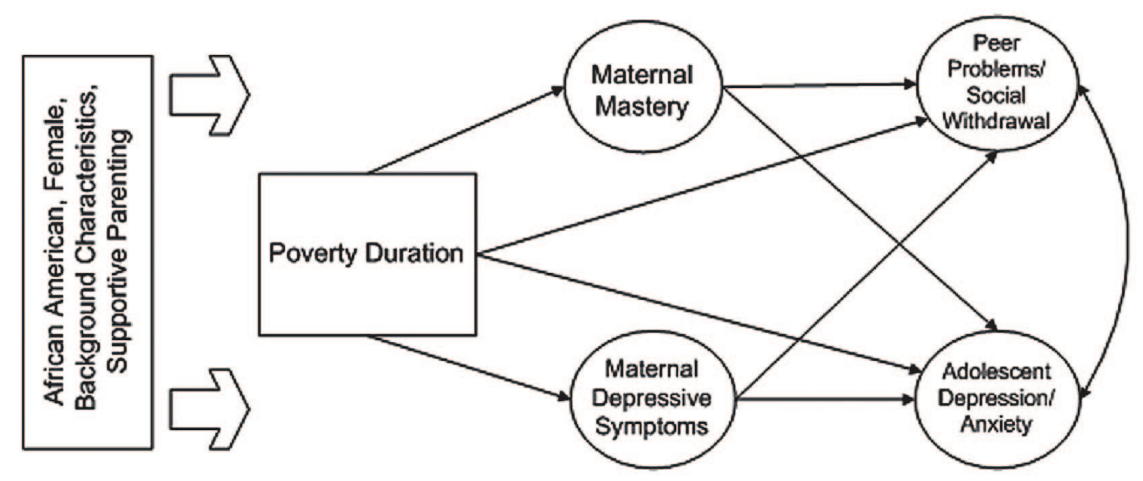

Figure 1. African American, Female, Background Characteristics, Supportive Parenting.

role in the well-being of adolescents and are consequently addressed as mediators. These symptoms directly and indirectly affect adolescents' later outcomes through parenting behavior. The research in the analytic portion of this article is oriented around the following questions: (a) Does poverty duration increase adolescent depression and anxiety and peer problems? (b) Do mothers' levels of depression and mastery mediate this association? That is, does poverty predict and operate through mother's depression and mastery? (c) Relative to other predictors, how powerful is poverty in predicting maternal depression and mastery, and how strongly related to adolescent outcomes is poverty relative to predictors once maternal depression and mastery is incorporated into the model?

\section{Data Source}

The data for this study are from the NLSY79 collected by The Center for Human Resource Research (CHRR) at the Ohio State University. NLSY data collection began in 1979 with an original sample of more than 12,600 respondents between the ages of 14 and 21. The survey includes extensive information on employment, education, training, and family experiences, and beginning in 1982, the survey also included information about pregnancy, postnatal fertility, and childcare experiences of the female respondents. The NLSY sample includes an oversample of African Americans and low-income families. In 1986, the survey began biennial assessments of the children born to NLSY79 mothers. 
The child assessments administered to NLSY families include (a) The Mother Supplement, (b) the Child Supplement, and (c) the Child Self-Administered Supplement (for children ages 10 and older). The instruments were administered to children of mothers in the original NLSY79 cohort under 15 years old. The Mother Supplement, completed by mothers of the children assessed, includes items from the Home Observation Measurement of the Environment (HOME), items on child's temperament, motor and social development, behavioral problems using the Behavioral Problems Index (BPI), and information on school and family background. The Child Supplement records information from the mother on child health and background along with responses from children to assessment items and interviewer observations of the child's home environment. This supplement included, in addition to items previously mentioned, the SelfPerception Profile for Children, Peabody Individual Achievement Test (PIAT) Math, and PIAT Reading Recognition and Comprehension. This sample includes 854 African American and Caucasian children ages 10 to 14 at the time of their assessment in 1998. Maternal background variables and assessments were compiled into a separate data set from child assessment files and were subsequently merged matching child data with their mothers' data.

\section{Analytic Strategy}

Analyses were conducted using, first, confirmatory factor analysis (CFA) to develop the appropriate measurement models and, second, structural equation modeling (SEM) to assess the regressions, including the CFA models and observed variables. The measurement models examine the extent to which the observed covariance between groups of items can be explained by a latent factor (e.g., depressive symptoms) and thus is analogous to traditional factor analytic techniques. However, the CFA is more useful than traditional factor analysis because by specifying an a priori model, the model fit can be assessed. Reported model fit indices include comparative fit index (CFI), the Tucker-Lewis Index (TLI), and the root mean square error approximation (RMSEA) following normative standards (Kaplan, 2000). A model is considered a good fit to the data if the CFI and TLI fit indices are higher than 0.95 and the RMSEA is less the .05, although a fit is considered adequate with an RMSEA between .05 and .08 (Browne \& Cudek, 1993; Kaplan, 2000). SEM is the ideal analysis in this instance because it allows (a) the use of multiple indicators to represent a latent construct/variable leading to a reduction in measurement error; (b) the analyses of multiple dependent variables simultaneously; (c) modeling mediating relation- 
ships, error terms, and test coefficients across multiple between subject groups; and (d) missing items on the dependent variables are handled flexibly (Bollen, 1989; Garson, 2003).

Total, direct, and indirect effects were estimated in both sets of models. ${ }^{1}$ The variances of all latent variables in the models are fixed to 1 so that coefficients represent the expected standard deviation difference in the outcome for a one-unit change in the independent variable and so that regressions among latent variables are fully standardized (i.e., effect sizes). Figure 1 illustrates the measurement model to be specified where the direct effects of poverty on maternal mastery and depressive symptoms as well as adolescent depression/ anxiety and peer problems are estimated. Furthermore, the mediating relationship of poverty, maternal mastery, and depressive symptoms on adolescent outcomes are analyzed.

\section{Measures}

Dependent measures. The BPI, developed by Zill and Petersen (1986), is employed to measure internalized and externalized behavioral outcomes. The BPI was administered to the mothers of children ages 4 to 14 in the sample using a battery of 28 questions. The battery includes five subscales, three of which measure external factors and two of which measure internal factors. Drawing on a subset of items, two scales were used to create the following latent variables: (a) depression/anxiety and (b) peer problems/social withdrawal. As the items for both factors are ordinal, rather than assuming item-level normality, the items were modeled using weighted least squares ordered probit equations. The latent underlying factor distributions of depression/anxiety and peer problems are assumed normal in the population (du Toit, 2003).

The depression/anxiety CFA construct identified with six items, including questions such as "Is the child sad, unhappy, or depressed, and is the child high-strung, tense, and nervous?" with responses ranging from 3 for often true to 1 for never true. BPI items were originally coded as 1 for often true, 2 for sometimes true, and 3 for never true. All BPI items were reverse coded to provide more meaningful results in the analyses. These measures together demonstrated a strong model fit by normative standards $(\mathrm{CFI}=.993, \mathrm{TLI}=.993$, and RMSEA $=.042){ }^{2}$

Peer problems and social withdrawal also included six items that assessed child social interaction, with queries such as "Child is withdrawn" and "Child has trouble getting along with other children." The model fit was acceptable for this factor (CFI $=.983$, TLI $=.977$, and RMSEA $=.065)$, indicating that the latent variable model adequately describes the observed data. 
Latent maternal measures. Mother's psychological resources are treated as mediating variables between economic hardship and adolescent mental health and also serve as an outcome of interest in addressing how a mother's poverty experiences and background affect her mental health. The Center for Epidemiologic Studies Depression Scale (CES-D) is a scale self-reported by the mother and was designed to measure current levels of depressive symptomatology (Radloff, 1977). The measure was administered biennially beginning in 1992. The CES-D consists of a battery of seven items asking about symptoms related to stress, such as trouble concentrating, feelings of depression, and sleeplessness. The mother is asked how often she experiences each of these feelings during the course of a week. The responses are coded 1 for none to one to two times daily, 2 for occasionally/three to four times daily, and 3 for most of the time/5 to 7 days. The confirmatory model using these items fit the model well (CFI $=.994$, TLI $=.990$, and RMSEA $=.022$ ).

The mastery scale measured in 1992 was created by Pearlin and Schooler (1978) to measure the extent to which the person feels she has control over events in her life. The seven items include respondent's feelings of helplessness in solving problems in her life, responses to whether she is capable of changing important things in her life, and the respondent's answers about whether there are ways for her to solve problems in her life. The mother's responses are coded 1 for strongly disagree/disagree and 2 for agree/strongly agree. Together, these items exhibit a covariance structure consonant with theoretical expectations $(\mathrm{CFI}=.975$, TLI $=.957$, and RMSEA $=.036$ ), suggesting that overall the single factor model fit the data sufficiently well.

Independent measures. Poverty status was measured using a dichotomous scale. Every year, the NLSY determines the poverty status of the household based on a ratio that compares gross household income to the federal poverty level of that year while taking family size into account (CHHR, 1999). For every year from 1979 to 1998, if the household was below the poverty line, the adolescent was coded as 1 for the in poverty classification. If they fall above the poverty line, they are coded as 0 for not in poverty. The duration of poverty status is calculated as the proportion of years reported in poverty. Poverty duration includes all years of poverty status reported from the birth of the child (1984 to 1988) to 1998.

The supportive parenting variable uses the Emotional Support subscale from the HOME Short Form adapted from the HOME Inventory developed by Bradley and Caldwell (1984). The variable, a total score, was created based on scores derived from observed parenting behaviors of mothers of focal children in the sample. The measure, constructed by 
CHRR, takes into account mother's behavior toward their youth during observation as well as self-reports of mother's use of discipline (CHRR, 2000). The overall instrument is meant to measure both child behavior and contextual factors, including parenting behavior and physical context to assess child developmental outcomes using two dimensions: (a) cognitive stimulation and (b) emotional support. Although cognitive stimulation has not been found to predict youth socioemotional outcomes, emotionally supportive parenting (e.g., responsiveness and warmth) has shown a significant relationship with adolescent well-being and therefore is included in the model (Goosby, 2003; Gutman et al., 2005; Kim et al., 2003; McLoyd, 1998).

Child and mother background measures. Child background characteristics used in this study include gender, race, and the child's age in years at the time of the most recent assessment. Sex is coded 0 for male and 1 for female. Race in the full sample analyses is used as a control variable and is coded 0 for Caucasian adolescents and 1 for African American adolescents.

Socioeconomic status is multidimensional and is associated with psychological well-being and children's later socioemotional and economic outcomes (Podruvska et al., 2005). Mother's cognitive ability, level of education, and age at first child's birth are also included as controls. Mother's cognitive ability is measured by the Armed Forces Qualification Test (AFQT), administered to NLSY mothers in 1980. Mother's educational attainment is measured by the number of years of schooling completed by the mother at the child's administered assessment. Mother's age (in years) at the child's birth was controlled because of the large portion of mothers in the NLSY who were adolescent when they had their children.

The relationship between psychological distress and socioeconomic status is especially strong among single mothers, whether their status is due to never being married or experiencing divorce (McLoyd, 1990). Single mothers are at great risk for anxiety, depression, and health problems (Compas \& Williams, 1990), and these risks are intensified by being poor and living alone with their children (McLoyd, 1990). Because of these findings, family structure is incorporated by creating three marital status categories. In the NLSY, marital status was originally coded using five categories: married, single, separated, divorced, and widowed. Arrays were created to construct three variables that were defined as always married, never married, and marital transition. In each of the categories, a formula was used to score a 0 or 1 according to the respondent's answers to the question at multiple time points. In the never married category, if a mother marks being single in 
every year of data collection, she was given a score of 1 . If she answered in any other category, she was given a score of 0 . The same logic was used for the remaining categories. For the marital transition variable, if a mother scores divorced, widowed, or separated in any given year of data collection, she receives a score of 1 . If she answers married or single for all survey years, she receives a score of 0 . The always married variable is the reference category.

\section{Results}

Table 1 reports the means and standard deviations for the characteristics of the overall sample and the sample separated by race. Included were $t$ tests on all continuous variables to tests mean differences of the sample by race, and chi-square tests of independence were used for dichotomous variables sex and the three marital status categories. On most background characteristics, the differences between African Americans and Caucasians were statistically significant, supporting previous literature that African Americans are disproportionately represented in low-income populations, thus the marked differences in background characteristics. In the overall sample, on average, young adolescents spent $23 \%$ of their lives in poverty. However, the difference between Caucasian and African American adolescents is pronounced, with African Americans spending on average $40 \%$ of their lives in poverty and Caucasian adolescents spending an average of $14 \%$ of their lives in poverty. African Americans and Caucasians also varied significantly on marital status, AFQT scores, and age at the first birth of their children.

\section{Multivariate Analysis}

Figure 1 illustrates the paths estimated in Tables 2 and 3. In each model, the dependent variables (a) peer problems/social withdrawal and (b) adolescent depression/anxiety are estimated simultaneously but for simplicity are discussed separately. Table 2 reports the results, analyzing first the direct effects of poverty duration on adolescent outcomes after controlling for race and gender and second the direct effects of maternal mastery and depressive symptoms on adolescent outcomes before and after controlling for background characteristics. Table 3 reports the portion of Figure 1 illustrating the direct effects of poverty duration on maternal mastery and depressive symptoms. These paths are estimated simultaneously with Models 3 and 4 in Table 2 and as a result are labeled 
Table 1. Descriptive Statistics $(N=854)$

\begin{tabular}{|c|c|c|c|c|}
\hline Independent Variable & $\begin{array}{c}\text { Total } \\
N=854 \\
\text { Mean (SD) }\end{array}$ & $\begin{array}{c}\text { African American } \\
n=313 \\
\text { Mean (SD) }\end{array}$ & $\begin{array}{c}\text { Caucasian } \\
n=541 \\
\text { Mean (SD) }\end{array}$ & $\begin{array}{r}\text { Chi-square/ } \\
t \text {-Test }{ }^{\text {a }}\end{array}$ \\
\hline \multicolumn{5}{|l|}{ Adolescent variables } \\
\hline African American & $37 \%$ & & & \\
\hline Female & $53 \%$ & $54 \%$ & $52 \%$ & .08 \\
\hline Child Age & $\begin{array}{l}12.19 \\
(1.30)\end{array}$ & $\begin{array}{l}12.15 \\
(1.23)\end{array}$ & $\begin{array}{l}12.17 \\
(1.29)\end{array}$ & 0.21 \\
\hline \multicolumn{5}{|l|}{ Mother variables } \\
\hline Poverty duration & $\begin{array}{l}23 \% \\
(0.31)\end{array}$ & $\begin{array}{l}40 \% \\
(0.34)\end{array}$ & $\begin{array}{l}14 \% \\
(0.24)\end{array}$ & $-12.70^{* * *}$ \\
\hline Married $^{\mathrm{b}}$ & $45 \%$ & $40 \%$ & $77 \%$ & $116.97(1)^{* * *}$ \\
\hline Never married & $11 \%$ & $25 \%$ & $3 \%$ & $98.28(1)^{* * *}$ \\
\hline Divorced & $44 \%$ & $35 \%$ & $20 \%$ & $24.70(1)^{* * *}$ \\
\hline Years of schooling & $\begin{array}{l}13.09 \\
(3.52)\end{array}$ & $\begin{array}{l}12.89 \\
(5.02)\end{array}$ & $\begin{array}{l}13.25 \\
(2.21)\end{array}$ & 1.27 \\
\hline AFQT score & $\begin{array}{c}41.19 \\
(28.38)\end{array}$ & $\begin{array}{c}21.19 \\
(17.65)\end{array}$ & $\begin{array}{c}52.76 \\
(26.95)\end{array}$ & $18.55^{\star * *}$ \\
\hline Age at first birth & $\begin{array}{l}22.39 \\
(3.25)\end{array}$ & $\begin{array}{l}20.97 \\
(3.23)\end{array}$ & $\begin{array}{l}23.21 \\
(2.98)\end{array}$ & $10.28^{* * *}$ \\
\hline Emotional support to child & $\begin{array}{l}111.97 \\
(18.88)\end{array}$ & $\begin{array}{l}102.68 \\
(20.11)\end{array}$ & $\begin{array}{l}117.35 \\
(15.82)\end{array}$ & $11.79 * * *$ \\
\hline
\end{tabular}

a. Degrees of freedom in parentheses for Chi-square results.

b. Always married is the omitted category.

$* * * \quad p<.001$

accordingly. Finally, the last section discusses the mediating influence of maternal mastery and depressive symptoms on the relationship between poverty and adolescent outcomes (see Figure 2).

Adolescent peer problems/social withdrawal and depression/anxiety. In addressing the relationship of poverty with peer problems/social withdrawal, after controlling for race and sex in Model 1, Model 2 shows that poverty duration has a highly significant relationship with peer problems/social withdrawal. ${ }^{3}$ Before introducing poverty duration in Model 2, African Americans and males scored significantly higher on peer problems/social withdrawal in Model 1. Race is no longer significant after controlling for poverty duration, whereas males continue to score sig- 
Table 2. Estimated Direct Effects of Adolescent Race and Sex, Poverty Duration, Maternal Depressive Symptoms, Mastery, and Background on Adolescent Outcomes $(N=834)$

\begin{tabular}{|c|c|c|c|c|}
\hline & Model 1 & Model 2 & Model 3 & Model 4 \\
\hline \multicolumn{5}{|c|}{ Peer Problems/Social Withdrawal } \\
\hline African American & $.277(.103) * * *$ & $.097(.109)$ & $.102(.115)$ & $-.017(.135)$ \\
\hline Female & $-.180(.090) * * *$ & $-.197(.091) * * *$ & $-.209(.096) * * *$ & $-.205(.098) * * *$ \\
\hline Poverty duration & & $.696(.165) * * *$ & $.312(.182)$ & $.288(.212)$ \\
\hline \multicolumn{5}{|l|}{ Maternal Depressive } \\
\hline Symptoms & & & $.237(.057) * * *$ & $-.205(.053) * * *$ \\
\hline Maternal Mastery & & & $-.257(.058) * * *$ & $-.244(.054) * * *$ \\
\hline Supportive parenting & & & & $-.012(.003) * * *$ \\
\hline Never married & & & & $-.340(.195)$ \\
\hline Divorced & & & & $.107(.113)$ \\
\hline Years of schooling & & & & $.009(.022)$ \\
\hline AFQT & & & & $.004(.003)$ \\
\hline Age at first birth & & & & $-.017(.019)$ \\
\hline Child age & & & & $-.005(.037)$ \\
\hline \multicolumn{5}{|l|}{ Depression/Anxiety } \\
\hline African American & $.013(.096)$ & $-.109(.098)$ & $-.114(.104)$ & $-.203(.123)$ \\
\hline Female & $-.110(.082)$ & $-.120(.082)$ & $-.126(.087)$ & $-.111(.089)$ \\
\hline Poverty duration & & $.470(.160)^{* * *}$ & $.078(.071)$ & $.080(.193)$ \\
\hline \multicolumn{5}{|l|}{ Maternal Depression } \\
\hline Symptoms & & & $.222(.056) * * *$ & $.200(.052) * * *$ \\
\hline Maternal Mastery & & & $-.262(.054) * * *$ & $-.244(.048) * * *$ \\
\hline Supportive parenting & & & & $-.011(.003) * * *$ \\
\hline Never married & & & & $-.156(.187)$ \\
\hline Divorced & & & & $.025(.109)$ \\
\hline Years of schooling & & & & $-.017(.020)$ \\
\hline AFQT & & & & $.005(.002)$ \\
\hline Age at first birth & & & & $-.003(.018)$ \\
\hline Child Age & & & & $.002(.033)$ \\
\hline \multicolumn{5}{|l|}{ Summary Statistics } \\
\hline Latent $R^{2}$ Peer & .025 & .061 & .163 & .191 \\
\hline $\begin{array}{l}\text { Latent } R^{2} \\
\text { Depression/Anxiety }\end{array}$ & .003 & .021 & .124 & .140 \\
\hline
\end{tabular}

AFQT $=$ Armed Forces Qualification Test

$* * * p<.001$

nificantly higher even after controlling for child age, level of emotional support, and maternal background characteristics, including maternal marital status, education, and age of the mother at her first birth. Fur- 
Table 3. Estimated Direct Effects of Poverty Duration and Maternal Background Characteristics on Maternal Depressive Symptoms and Mastery

\begin{tabular}{lcc}
\hline & Model 3 & Model 4 \\
\hline Maternal Depressive Symptoms & & \\
$\quad$ Poverty duration & $.810(.146)^{* * *}$ & $.471(.177)^{* * *}$ \\
African American & & $-.138(.114)$ \\
Female & & $-.116(.077)$ \\
Never married & $.091(.162)$ \\
Divorced & & $.140(.105)$ \\
Years of schooling & & $.036(.019)$ \\
AFQT & $-.914(.149)^{* * *}$ & $-.007(.002)^{* * *}$ \\
Age at first birth & & $-.009(.015)$ \\
Maternal Mastery & & $-.442(.191)^{* * *}$ \\
Poverty duration & & $.285(.115)^{* * *}$ \\
African American & $.006(.078)$ \\
Female & & $-.008(.187)$ \\
Never married & & $.103(.112)$ \\
Divorced & & $.035(.018)^{* * *}$ \\
Years of schooling & $.006(.002)^{* * *}$ \\
AFQT & $.039(.016)$ \\
Age at first birth & .060 & .083 \\
Summary Statistics & .075 & .115 \\
Latent $R^{2}$ Maternal Depressive Symptoms & \\
Latent $R^{2}$ Maternal Mastery & & \\
\hline AFQT Armed For & & \\
\hline
\end{tabular}

AFQT $=$ Armed Forces Qualification Test

$* * * \quad p<.001$

thermore, when the direct effects of maternal depressive symptoms and mastery are introduced into the model, poverty duration is reduced by $56 \%$ and explains approximately an additional $10 \%$ of the variance. Both maternal depressive symptoms and mastery are highly significant, with youth reporting .24 SDs higher on peer problems/social withdrawal for every standard deviation increase in maternal depressive symptoms. Similarly, for each unit increase in maternal mastery, adolescents score .26 SDs lower on peer problems/social withdrawal. The relationship remains salient after all covariates are introduced into Model 5. Even after controlling for emotionally supportive behavior, a mechanism through which maternal mental health can manifest itself, maternal psychological resources remains statistically significant at approximately the same 


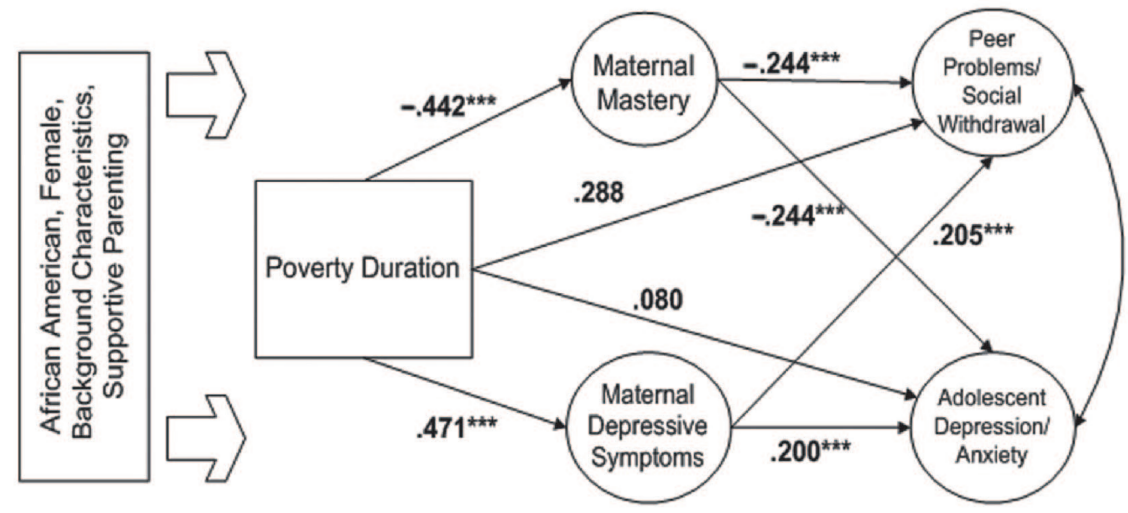

Figure 2. Fully Estimated Model Predicting Peer Problems/Social Withdrawal and Adolescent Depression/Anxiety. $\chi^{2}(140)=352.57$; RMSEA $=.042 .{ }^{*} p<.05$; ${ }^{* *} p<.01 ;{ }^{* *} p<.001$

magnitude. These models lend strong evidence for the importance of maternal psychological resources in influencing adolescent peer problems/ social withdrawal.

A similarly striking pattern was found in the analyses estimating the direct effects on adolescent depression/anxiety, where a youth who spends his or her entire life in poverty scores almost a half of a standard deviation higher on depression/anxiety relative to a youth who spends none of his or her life in poverty in Model 2. However, when maternal depressive symptoms and mastery are introduced in Model 3, the poverty duration coefficient was reduced $83 \%$ and rendered nonsignificant, demonstrating the relationship between poverty and maternal mental health and the relationship between maternal mental health and adolescent well-being. In results parallel to that of peer problems/social withdrawal, maternal psychological resources explained an additional $10 \%$ of the variance between Models 2 and 3, and very little was contributed by controlling for all other covariates.

Poverty, mother's depression, and mastery and mediating effects. Table 3 details the direct effects of poverty duration on maternal depressive symptoms and mastery. The results show support for the literature suggesting that poverty increases the prevalence of psychological distress, depressive symptoms, and sense of powerlessness. Mothers who spend the duration of their children's lives in poverty score .81 SDs higher on 
depressive symptoms in Model 3 before controlling for background characteristics in Model 4, yet poverty duration remains highly significant after controlling for the mother's background characteristics and the sex of her child. Likewise, there are similar results for maternal mastery, where mothers who experience the duration of their children's lives in poverty report almost a standard deviation lower score on mastery relative to mothers who spend none of their children's lives in poverty, illustrating that as time in poverty increases, mothers experience a decline in their sense of control over their lives. This remains the case after controlling for background characteristics.

Figure 2 reports the findings of the fully estimated Model (Model 4 in Tables 2 and 3), including the control of additional background covariates, and addresses the question of the mediating influence maternal depression and mastery have on the relationship between poverty duration and adolescent socioemotional outcomes. Consistent with prior research on the impact of maternal psychological well-being and adolescent outcomes, maternal psychological resources explain a substantial portion of the effect of poverty duration in this model. Based on the combined indirect effects of poverty duration on mastery, poverty duration on maternal depressive symptoms, maternal mastery on peer problems/social withdrawal, and maternal depressive symptoms on peer problems, approximately $42 \%$ of the total effect of poverty on adolescent peer problems operates through the indirect effects of poverty, mastery, and maternal depressive symptoms. The total effect is based on the sum of all indirect and direct effects of independent endogenous variables on dependent exogenous variables (Maruyama, 1998). In addition, $71 \%$ of the total effect of poverty on adolescent depression/anxiety operates through maternal mastery and depressive symptoms, illustrating the substantial impact that maternal psychological resources have on the well-being of her children.

\section{Discussion}

This study expands on the current literature examining the role of poverty and maternal psychological resources on adolescent socioemotional outcomes by examining the following questions: (a) To what extent does poverty directly affect adolescent outcomes, (b) to what extent does maternal mental health affect adolescent outcomes, (c) does maternal mental health mediate poverty's effect on adolescent outcomes, and (d) to what degree are maternal psychological resources actually predicted by poverty duration net of other correlated covariates? The findings of this study were consistent with prior research reporting significant direct 
effect of poverty on adolescent outcomes, with poor adolescents scoring markedly higher on depression/anxiety and peer problems/social withdrawal than their nonpoor counterparts (Bolger et al., 1995). In addition, maternal mastery and depressive symptoms were also strongly associated with adolescent outcomes, supporting the literature that maternal mental health is an important predictor of child and adolescent well-being (McLoyd, 1998).

The most compelling findings are those examining the mediating impact of maternal psychological resources on the relationship between poverty duration and adolescent psychological resources. Prior literature examining the relationship between maternal mental health and adolescent outcomes emphasizes how maternal psychological resources affect youth through behavioral manifestations (Conger et al., 1994; Gutman et al., 2005; McLoyd, 1998). Parenting behavior and emotional support are seen as the primary impact of maternal mental health on adolescent outcomes, as parents who are in poverty tend to experience increased levels of stress that lead to harsh and inconsistent parenting (Lempers et al., 1989). The analyses presented here report the magnitude of the direct impact of maternal mental health on adolescent socioemotional outcomes and find that maternal mastery and depressive symptoms explain a considerable amount of the poverty effect on adolescent depression/ anxiety and peer problems/social withdrawal even after controlling for parenting behavior. These findings are consistent with those reported by McLeod and Owens (2004), who found that maternal mental health consistently helped to explain the effects of maternal psychological resources on both Black and Caucasian children in poverty.

Although emotionally supportive parenting is important in explaining a portion of the maternal mental health relationship on adolescent mental health in the context of poverty, continued research is needed to more rigorously examine (a) the operationalization of parenting behaviors to parcel out the most deleterious behaviors as well the behaviors that serve as buffers and (b) other mechanisms through which maternal mental health may affect adolescent well-being. Previous studies have reported that parent psychological distress mediates the relationship between economic hardship and parent-adolescent relationships, family warmth, and mother-adolescent conflict (Gutman et al., 2005; Vandewater \& Lansford, 2005). However, although these studies report informative process models, including measures of parenting relations with their children, they do not report the remaining impact of maternal mental health after taking into account the parenting behaviors and other contextual factors. 
After taking into account the background characteristics of mothers in these analyses, poverty duration continues to predict a substantial amount of maternal mastery and depressive symptoms even after controlling for covariates including race, marital status, and age at the birth of their first child, factors that are correlated with maternal mental health. This supports prior research that found economic strain and hardship are highly correlated with maternal psychological well-being (McLoyd, 1990; Taylor \& Roberts, 1995). Moreover, the analyses demonstrated that for mastery, African American mothers have higher levels of mastery than do comparable Caucasians. This finding suggests that African American mothers may have developed more appropriate, adaptive coping strategies when experiencing persistent poverty.

In this sample, on average, African American mothers spend more time in poverty than Caucasian mothers, which reflects the trends of African Americans being disproportionately represented and more persistently living in poverty. However, African American women may be less likely to be socially isolated and may have kinship support in their community (McAdoo, 1997). This in turn may lead to African American mothers feeling that they have more control over their lives because of the additional supports of adaptive strategies through others who may help with caregiving. These differences in the characteristics of poverty experiences among African American and Caucasian mothers suggest the importance of additional contextual factors that could play a role in the lives of low-income families and may potentially alleviate the challenges associated with maternal mental health.

The cumulative exposure model posed by McLoyd (1998) states that the constant strain of ongoing exposure to poverty has detrimental effects on both parents and their children. Such exposure is typically associated with living in areas that have a high concentration of poverty and living in areas that lack institutional resources and support. In addition, on an individual level, people who are in poverty for extended periods of time may experience higher levels of stress and mental and physical health problems, which in turn influence their ability to parent effectively. This argument is supported by the body of research finding that among low-income and some minority populations, reports of depression and posttraumatic stress disorder are especially high. Among single mothers, during a 12-month period, the prevalence of mental health disorders falls between one third and one half (Meisel, Chandler, \& Rienzi, 2003). With such a high prevalence of risk factors in this population, continued research is needed along with interventions to improve the wellbeing of both poor adolescents and their mothers.

This study does have limitations in how maternal depression and mastery were measured. Maternal mental health outcomes, including de- 
pressive symptoms and mastery, were measured at a single point in time. Depressive symptomatology has been shown to be cyclical (Pearlin \& Schooler, 1978) or more likely to surface more than once. I have assumed that there may be a lag in the effects of depressive symptoms or that mothers who score high on depressive symptoms are more likely to score high again later. The only way to truly test this assumption is to measure maternal mental health at more than one point in time. ${ }^{4}$ This also leads to the issue of causality with regard to maternal mental health and family context effects, which are somewhat endogenous. Although the association between mental health and socioeconomic status has been established, this study cannot assess the causal relationship between maternal mental health and poverty experiences.

In summary, the findings indicate that persistent poverty has deleterious effects on both adolescent socioemotional problems and maternal psychological resources. Moreover, a substantial portion of poverty duration's impact on adolescent peer problems/social withdrawal and depression/anxiety is mediated by maternal psychological resources $(42 \%$ and $71 \%$, respectively). The portion of the dependent variables' variance explained by maternal psychological resources are higher than the variance of all other covariates included in the model combined. The results clearly demonstrate not only the deleterious direct impact of poverty on adolescent outcomes but also the importance of family processes in the lives of poor adolescents' continued development, specifically through maternal psychological well-being.

Adolescents who engage in problematic behavior in addition to being in poverty generally do not have the access to structural resources available to alleviate these problems. As a result, increased behavioral problems have more dire consequences for their later outcomes, including employment opportunities, school completion, and family formation. This study also finds that maternal psychological resources play an important role in reducing or exacerbating the deleterious consequences of persistent poverty on problematic adolescent outcomes, suggesting that with improved mental health, mothers can serve as a buffer to the strains and stressors associated with poverty. By increasing access to mental health resources for poor mothers, creating more effective treatments, and providing health-related information, well-being among children with lowincome mothers could improve. Furthermore, by alleviating economic strain for families in poverty, there can be changes in the economic and psychological well-being of families and youth.

\section{Notes}

1. It should be noted that there is an average of 1.4 children per mother in the sample, in- 
dicating nesting within families. To account for the nonindependence of observations because of clustering, all previous and subsequent structural equation modeling (SEM) analyses adjust standard errors and estimates of model fit using robust estimators (Munthén \& Munthén, 2004; these analyses use the Mplus v4 "type = complex" analysis).

2. Full scales are provided on request to the author.

3. In further analyses, an interaction between race and gender was included that rendered the main effects nonsignificant. Because the interaction was not significant, it was not reported.

4. After 1992, the Center for Epidemiologic Studies Depression Scale was administered to mothers ages 40 and older, which substantially reduced the number of mothers in the sample, because many were younger than 40 in 1994. As a result, it was not possible to test the causal relationship between youth behavior and maternal mental health.

\section{References}

Bolger, K. E., Patterson, C. J., Thompson, W. W., \& Kupersmidt, J. B. (1995). Psychosocial adjustment among children experiencing persistent and intermittent family economic hardship. Child Development, 66, 1107-1129.

Bollen, K. A. (1989). Structural equations with latent variables. New York: Wiley Press.

Bradley, R. H., \& Caldwell, B. M. (1984). Home observations for measurement of the environment. Little Rock: University of Arkansas at Little Rock.

Brooks-Gunn, J., \& Furstenberg, F. F. (1989). Adolescent sexual behavior. American Psychologist, 44, 249-257.

Browne, M., \& Cudek, R. (1993). Alternative ways of assessing model fit. In K. Bollen \& J. Long (Eds.), Testing structural equation models (pp. 136-162). Newbury Park, CA: Sage.

Center for Human Resource Research. (1999). NLSY79 user's guide. Columbus: The Ohio State University.

Center for Human Resource Research. (2000). NLSY79 1998 child and young adult data: User's guide. Columbus: The Ohio State University.

Compas, B. E., \& Williams, R. A. (1990). Stress, coping, and adjustment in mothers and young adolescents in single- and two-parent families. American Journal of Community Psychiatry, 18, 525-545.

Conger, R. D., Ge, X., Elder, G. H., Lorenz, F. O., \& Simons, R. L. (1994). Economic stress, coercive family processes, and developmental problems in adolescents. Child Development, 65, 541-561.

Duncan, G. J., \& Brooks-Gunn, J. (Eds.). (1997). The consequences of growing up poor. New York: Russell Sage.

Duncan, G. J., Brooks-Gunn, J., \& Klebanov, P. (1994). Economic deprivation and early childhood development. Child Development, 65, 296-318.

du Toit, M. (Ed.). (2003). IRT from SSI: BILOG-MG MULTILOG PARSCALE TESTFACT. Lincolnwood, IL: Scientific Software International, Inc.

Elder, G. H. (1999). Children of the great depression: Social change in life experiences (25th Anniversary Edition). Boulder, CO: Westview.

Ensminger, M. E. (1995). Welfare and psychological distress: A longitudinal study of African American urban mothers. Journal of Health and Social Behavior, 36, 346-359.

Garson, G. D. (2003). Structural equation modeling. Retrieved March 25, 2006, from http://www2.chass.ncsu.edu/garson/pa765/structur.htm 
Goosby, B. J. (2003). The impact of poverty duration on youth behavioral and cognitive outcomes. Unpublished Doctoral Dissertation, Pennsylvania State University, University Park, PA.

Gutman, L. M., McLoyd, V. C., \& Tokoyawa, T. (2005). Financial strain, neighborhood stress, parenting behaviors, and adolescent adjustment in urban African American families. Journal of Research on Adolescence, 15, 425-449.

Haveman, R., \& Wolfe, B. (1994). Succeeding generations: On the effects of investments in children. New York: Russell Sage.

Jayakody, R., \& Stauffer, D. M. (2000). Mental health problems among single mothers: Implications for work and welfare reform. Journal of Social Issues, 56, 617-634.

Kaplan, D. (2000). Structural equation modeling: Foundations and extensions. Thousand Oaks, CA: Sage.

Kim, I. J., Ge, X., Brody, G. H., Conger, R. D., Gibbons, F. X., \& Simons, R. L. (2003). Parenting behaviors and the occurrence and co-occurrence of depressive symptoms and conduct problems among African American children. Journal of Family Psychology, 17, 571-583.

Korenman, S., Miller, J., \& Sjaastad, J. (1995). Long-term poverty and child development in the United States: Results from the NLSY. Children and Youth Services Review, 17, 127-155.

Lempers, J., \& Clark-Lempers, D. (1990). Family economic stress, maternal and paternal support and adolescent distress. Journal of Adolescence, 13, 217-229.

Lempers, J., Clark-Lempers, D., \& Simons, R. R. (1989). Economic hardship, parenting distress in adolescence. Child Development, 60, 25-49.

Lichter, D. T., Qian, Z., \& Crowley, M. L. (in press). Poverty and economic polarization among America's minority and immigrant children. In R. Crane \& T. Heaton (Eds.), Handbook of families and poverty: Interdisciplinary perspectives. New York: Sage.

Liem, R., \& Liem, J. (1978). Social class and mental illness reconsidered: The role of economic stress and social support. Journal of Health and Social Behavior, 19, 139-156. Luthar, S. S. (1999). Poverty and children's adjustment. Thousand Oaks, CA: Sage.

Maruyama, G. M. (1998). Basics of structural equation modeling. Thousand Oaks, CA: Sage.

McAdoo, H. P. (1997). Black families (3rd ed.). Thousand Oaks, CA: Sage.

McLeod, J. D., \& Nonnemaker, J. M. (2000). Poverty and child emotional and behavioral problems: Racial and ethnic differences in process and effects. Journal of Health and Social Behavior, 41, 137-161.

McLeod, J. D., \& Owens, T. (2004). Psychological well-being in the early life-course: Variations by socioeconomic status, gender, and race/ethnicity. Social Psychology Quarterly, 67, 257-278.

McLeod, J. D., \& Shanahan, M. J. (1993). Poverty, parenting, and children's mental health. American Sociological Review, 58, 351-366.

McLeod, J. D., \& Shanahan, M. J. (1996). Trajectories of poverty and children's mental health. Journal of Health and Social Behavior, 37, 207-220.

McLoyd, V. C. (1990). The impact of economic hardship on Black families and children: Psychological distress, parenting, and socioemotional development. Child Development, 61, 311-346.

McLoyd, V. C. (1998). Socioeconomic disadvantage and child development. American Psychologist, 53, 185-204.

McLoyd, V. C., Jayaratne, T. E., Ceballo, R., \& Borquez, J. (1994). Unemployment and work interruption among African American single mothers: Effects on parenting and adolescent socioemotional functioning. Child Development, 65, 562-589.

Meisel, J., Chandler, D., \& Rienzi, B. M. (2003). Domestic violence prevalence and ef- 
fects on employment in two California TANF populations. Violence Against Women, 9, 1191-1212.

Menaghan, E. G., Kowaleski-Jones, L., \& Mott, F. L. (1997). The intergenerational costs of parental social stressors: Academic and social difficulties in early adolescence for children of young mothers. Journal of Health and Social Behavior, 38, 72-86.

Miech, R. A., Avshalom, C., Moffitt, T. E., Wright, B. R., \& Silva, P. A. (1999). Low socioeconomic status and mental disorders: A longitudinal study of selection and causation during young adulthood. American Journal Sociology, 104, 1096-1131.

Mirowsky, J., \& Ross, C. (1989). Social causes of psychological distress. New York: Aldine de Gruyter.

Mistry, R. S., Vandewater, E., Huston, A. C., \& McLoyd, V. C. (2002). Economic wellbeing and children's social adjustment: The role of family process in an ethnically diverse low-income sample. Child Development, 73, 935-951.

Moffitt, R. A. (2002). From welfare to work: What the evidence shows (Policy Brief No. 13, January. Welfare Reform and Beyond). Washington, DC: Brookings Institution. Munthén, L. K., \& Munthén, B. O. (2004). Mplus user's guide (3rd ed.). Los Angeles: Author.

Pearlin, L. I. (1999). The stress process revisited: Reflections on concepts and their interrelationships. In C. S. Aneshensel \& J. C. Phelan (Eds.), Handbook of the sociology of mental health (pp. 395-416). New York: Kluwer Academic/Plenum.

Pearlin, L. I., \& Schooler, C. (1978). The structure of coping. Journal of Health and Social Behavior, 19, 2-21.

Podruvska, T., Shieman, S., Pearlin, L. I., \& Nguyen, K. (2005). The sense of mastery as a mediator and moderator in the association between economic hardship and health in later life. Journal of Aging and Health, 17, 634-660.

Radloff, L. S. (1977). The CES-D Scale: A self-report depression scale for research in the general population. Journal of Applied Psychological Measures, 1, 385-401.

Ross, C. E., \& Sastry, J. (1999). The sense of personal control: Social structural and causes and emotional consequences. In C. S. Aneshensel \& J. Phelan (Eds.), Handbook of sociology of mental health (pp. 369-395). New York: Kluwer Academic/Plenum Publishers.

Stiffman, A. R., Hadley-Ives, E., Elze, D., Johnson, S., \& Dore, P. (1999). Impact of environment on adolescent mental health and behavior: Structural equation modeling. American Journal of Orthopsychiatry, 69, 73-85.

Taylor, R., \& Roberts, D. (1995). Kinship support and maternal and adolescent wellbeing in economically disadvantaged African American families. Child Development, 66, 1585-1597.

U.S. Bureau of the Census. (2006). Retrieved October 4, 2006, from http://www.census.gov/hhes/www/poverty/histpov/hstpov4.html

Vandewater, E. A., \& Lansford, J. (2005). A family process model of problem behaviors in adolescents. Journal of Marriage and Family, 67, 100-109.

Wheaton, B. (1999). The nature of stressors. In A. V. Horwitz \& T. L. Scheid (Eds.), A handbook for the study of mental health (pp. 176-197). Cambridge, UK: Cambridge University Press.

Williams, D. (1999). Race, socioeconomic status, and health: The added effects of racism and discrimination. Annals of the New York Academy of Sciences, 896, 210-225.

Zill, N., \& Petersen, J. L. (1986). Behavioral problems index. Washington, DC: Child Trends, Inc. 